\title{
Plasticizing and Hydrophobizing Effect of Plant Oil- Based Acrylic Monomers in Latex Copolymers with Styrene and Methyl Methacrylate
}

\author{
Zoriana Demchuk ${ }^{1}$, Vasylyna Kirianchuk ${ }^{2}$, Kyle Kingsley ${ }^{1}$, Stanislav Voronov $^{2}$, Andriy Voronov ${ }^{1}$ \\ ${ }^{1}$ North Dakota State University, Department of Coatings and Polymeric Materials \\ Department 2760, P.O. Box 6050, Fargo, North Dakota, United States 58105-6050 \\ andriy.voronov@ndsu.edu \\ ${ }^{2}$ Lviv Polytechnic National University, Department of Organic Chemistry \\ 12 Bandera Street, Lviv, Ukraine 79013
}

\begin{abstract}
Latex nanoparticles from acrylic monomers (made from olive and soybean oil which are significantly different in terms of fatty acid unsaturation amount) were synthesized using miniemulsion copolymerization with styrene and methyl methacrylate. Presence of plant oil-based fragments impacts thermomechanical properties of latex films by decreasing glass transition temperature and creating a plasticizing effect. The thermomechanical properties of resulting latex nanoparticles depend considerably on the amount of incorporated oil-derived fragments. As a result, biobased ingredients make latex copolymers more flexible, improve material film forming properties, and provide flexibility and toughness when compared to the normally rigid polystyrene and poly(methyl methacrylate). In addition, plant oil-based fragments enhance hydrophobicity of the crosslinked latex films and can be considered as additives to reduce water sensitivity of the polymer network.
\end{abstract}

Keywords: Plant Oil-Based Monomers, Biobased Latexes, Internal Plasticizing, Hydrophobicity.

(C) Copyright 2018 Authors - This is an Open Access article published under the Creative Commons Attribution License terms (http://creativecommons.org/licenses/by/3.0). Unrestricted use, distribution, and reproduction in any medium are permitted, provided the original work is properly cited.

\section{Introduction}

Commodity plasticizers are low molecular nonvolatile compounds that are widely used as additives in polymer production [1]. The function of a plasticizer is to reduce the forces between the macromolecules, thereby increasing chain mobility and leading to polymer softening, which may facilitate better material processing. In the past decade, the world production of plasticizers has grown up to 5 million tons a year. Plasticizers are used in manufacturing of many polymer and polymeric materials for different types of applications [2]. Incorporation of a plasticizer in a polymer matrix decreases the material glass transition temperature $\left(T_{g}\right)$, tensile stress, hardness, density, viscosity, etc. The presence of plasticizer molecules leads to increased polymer and polymer network flexibility, as well as dielectric constant and resistance to damage, all of which can impact polymer crystallinity, transparency, electric conductivity, fire resistivity, and biodegradability [2-4].

According to the International Union of Pure and Applied Chemistry (IUPAC), the definition of a plasticizer is "a substance or material, which is incorporated in material (usually a plastic or an elastomer) to increase its flexibility and workability". The most widely used low molecular commodity plasticizer is di-(2-ethylhexyl) phthalate, also known as dioctyl phthalate. However, due to toxicity based on migration of small phthalate molecules from the polymer matrix (e.g. polyvinyl chloride [PVC]), utility of dioctyl phthalate in some applications is limited $[5,6]$. Fatty acid esters, benzoates, tartrates and chlorinated hydrocarbons, esters of adipic, azelaic, and sebacic acid are other commonly used types of plasticizers [7].

For the last few decades, the chemical industry has been looking for new plasticizers based on natural materials. Derived from biobased renewable resources, 29 
such plasticizers would be non-toxic and safe. Moreover, polymer-based plasticizers from natural resources (e.g. vegetable oils) may be less able to migrate from the material due to the higher level of intermolecular interactions between (macro)molecules of the plasticizer and polymer matrix. Already developed examples of biobased plasticizers include materials from epoxidized vegetable oils (soybean, linseed, castor, sunflower) and esters of fatty acids $[8,9]$. Fabra et al. demonstrated that the addition of oleic acid in hydrophilic caseinate films plasticizes the resulting material, improving the mechanical properties of the films and increasing their water permeability [10].

Fragments of plant oil-based acrylic monomers (POBMs) recently synthesized in our group while being incorporated in macromolecules impacted thermomechanical properties of the resulting copolymers by decreasing their $T_{g}$ [11,12]. This indicates that the presence of such constituents in the copolymer structure can provide internal plasticization effects, making the resulting materials more environmentally friendly compared to conventional products where low molecular phthalates are used.

The internal plasticization effect can be achieved by copolymerization of various commercial vinyl monomers with a library of POBMs developed in our group [11-13]. When long unsaturated fatty acid fragments $\left(\mathrm{C}_{18}\right)$ of POBMs are incorporated into the macromolecules, they can reduce the intermolecular interactions and increase intermolecular distance, thus increasing chain mobility and facilitating polymer softening (plasticizing).

Suitability of POBMs in free radical copolymerization reaction with other vinyl monomers was demonstrated in our previous study [11-13]. Considering the highly hydrophobic nature of POBMs and limited aqueous solubility, the miniemulsion process was employed for polymerization in this study. Miniemulsion polymerization occurs in nanosized droplets (nanoreactors) and results in formation of latex nanoparticles (latexes), one of the most advanced polymeric materials, which is widely used for making coatings and paints. In the miniemulsion process, copolymerization feasibility for hydrophobic monomers is provided by the large interfacial area between aqueous and oil phases where radical reactions can occur.

In this study, we report in more detail the internal plasticizing effect of incorporating plant oil-based fragments into latex copolymers. For this purpose, a range of biobased latexes (latex nanoparticles) from two POBMs (acryloyl aminoethyl oleate [OVM] and acryloyl aminoethyl soyate [SBM]) and two petroleumbased vinyl monomers (styrene [St] and methyl methacrylate [MMA]) were synthesized in miniemulsion polymerization. SBM and OVM are significantly different in terms of fatty acid fragment unsaturation because SBM is more unsaturated. To this end, the effect of POBM unsaturation amount on the thermal and mechanical properties of latex films was studied. In addition, the impact of incorporated biobased copolymer fragments on hydrophobicity of crosslinked latex films was evaluated in this work.

\section{Materials}

Olive oil (Pompeian Inc., Baltimore, MD), Soybean Oil (Crisco; The J.M. Smucker Company, Orville, OH), Nhydroxyethyl acrylamide (HEAAm; TCI America), sodium dodecyl sulphate (SDS; VWR, Solon, $\mathrm{OH}$ ) and 2,2'-Azobis(2-methyl-propionitrile) were used as received and stored at low temperature in the fridge. St and MMA (99\%, stab., Alfa Aesar, Heysham, England) were distilled under vacuum before use. The deionized water for the latex synthesis was produced by Mili-Q Integral Water Purification System (18MQ).

\section{Experimental Section}

\subsection{Plant Oil-Based Monomer (POBM) Synthesis}

Acrylic monomers from olive and soybean oil were synthesized using one-step transesterification reaction of $\mathrm{N}$-hydroxyethyl acrylamide with plant oil triglycerides in the presence of catalytic amounts of sodium hydroxide. The detailed synthesis procedure of POBM synthesis and its characterization are described in [11].

\subsection{Biobased Latex Synthesis}

The olive oil-based and soybean oil-based latexes were synthesized in miniemulsion copolymerization of respective acrylic monomers from plant oils with St and MMA. For this purpose, oil phase $(15 \mathrm{~g})$ was prepared by mixing of POBM (10-60wt\%, 1.5-9g) with MMA or St at different ratios $(6-13.5 \mathrm{~g})$ in the presence of $1.5 \mathrm{wt} \%$ $(0.225 \mathrm{~g})$ oil-soluble initiator.

The aqueous phase was formed by dissolving the emulsifier (SDS, 2-4wt\%) (0.3-0.6g) in Millipore water with added small amounts of $\mathrm{NaCl}(0.02 \mathrm{~mol} / \mathrm{l})(0.04 \mathrm{~g})$. The oil phase was added dropwise to the aqueous phase and mixed for $45 \mathrm{~min}$ to form pre-emulsion. The pre- 
emulsions were sonicated with three pulses for $60 \mathrm{sec}$ each using Q-Sonica ( $500 \mathrm{~W}$ digital sonicator, $1 / 2$ in. tip, $20 \mathrm{kHz}$, Newtown, CN) and placed in an ice bath to maintain the temperature at $25^{\circ} \mathrm{C}$. Resulting miniemulsions were purged with nitrogen for $10 \mathrm{~min}$ and polymerized at $60^{\circ} \mathrm{C}$ for $5 \mathrm{hr}$. The latex solid content was kept at $30 \mathrm{wt} \%$.

\subsection{Plant Oil-Based Latex Characterization}

Total monomer conversion was determined by multiple precipitation of latex in methanol in order to remove residual unreacted monomers. The purified copolymers were dried in an oven until constant weight was achieved.

The latex solid content was measured gravimetrically by drying the latex samples in an oven at elevated temperature for $45 \mathrm{~min}$.

The latex copolymer composition was analyzed using ${ }^{1} \mathrm{H}$ NMR spectroscopy (AVANCE III HDTM 400 high-performance digital NMR spectrometer, Bruker, Billerica, MA) using $\mathrm{CDCl}_{3}$ as a solvent.

Molecular weight of the copolymers was determined in gel permeation chromatography (GPC) (Waters Corporation Modular Chromatograph, consists of a Waters' 1515 HPLC pump, a Waters' 2410 refractive index detector, and two $10 \mu \mathrm{m}$ PL-gel mixed-B columns) at $40^{\circ} \mathrm{C}$ using tetrahydrofuran as a carrier solvent.

Particle size of the plant oil-based latex particles was measured using dynamic light scattering (Particle Sizing Systems Nicomp 380, Santa Barbara, CA) at a scattering angle of $90^{\circ}$ at room temperature.

The glass transition temperature of latexes was determined by differential scanning calorimetry (DSC) (TA Instruments Q1000 calorimeter) at heat/cool/heat mode $\left(-40^{\circ} \mathrm{C} / 150^{\circ} \mathrm{C}\right)$ with dry nitrogen purging through the sample at $50 \mathrm{~mL} / \mathrm{min}$ flow rate. The heating/cooling rate of latex samples was $10-20^{\circ} \mathrm{C} / \mathrm{min}$.

Latex free films were formed by applying latex to the clean glass substrate using a drawdown bar of 8 mils of thickness and curing at elevated temperature for 3-5 hours using autooxidation process. The resulting films were peeled off from the substrate after curing.

The unsaturation amount of latexes in monomer feed $\left(U_{M F}\right)$ was calculated using the approach described in [11].

The latex films were subjected to dynamic mechanical analysis (DMA; TA Instruments Q800) with a heating rate of $5^{\circ} \mathrm{C} / \mathrm{min}$ to investigate the dynamic mechanical behavior of plant oil-based latex films. The crosslink density of the latex films $(v)$ was calculated using rubber elasticity theory where the storage modulus $\left(G^{\prime}\right)$ is expressed by the equation below [14]:

$G^{\prime}=v \cdot R \cdot T=\left(\rho / M_{c}\right) \cdot R \cdot T$,

where $v$ is crosslink density in $\mathrm{mol} / \mathrm{cm}^{3}, R$ is gas constant, and $T$ is absolute temperature.

Molecular weight in $\mathrm{g} / \mathrm{mol}$ between crosslinks was determined using the equation:

$M_{c}=\rho / v$,

where $\rho$ is density of latex film.

Mechanical properties of latex films were tested using Instron tensile testing machine 2710-004 (maximum load $500 \mathrm{~N}$ ). The film samples had a rectangular shape (length: $25 \mathrm{~mm}$, width: $5 \mathrm{~mm}$ ). The thickness of the films was measured before each testing.

Performance of coatings based on synthesized latexes was tested by measuring the flexibility, hardness, and adhesion of the coating to the substrate. Flexibility of the latex coatings was evaluated using conical mandrel bend method according to American Society for Testing and Materials (ASTM) D522. It measures ability of coating to resist cracking when elongated. The hardness was tested using pendulum hardness method (ASTM D4366-16) where hardness of the organic coating is defined as the resistance of coating to the deformation by calculating the damping time of a pendulum which touches the coating surface. The plant oil-based latex coatings adhesion was identified by cross-hatch adhesion method (ASTM 3359) using a tape test.

The surface free energy of the latex coatings from olive oil-based and soybean oil-based monomers copolymerized with St or MMA was characterized by measuring the contact angle (five measurements for each sample) of water and diiodomethane on the coating surface using FTA 125 contact angle/surface energy analyzer. Surface free energy of each coating was calculated using Owens and Wendt's modification of Young's equation [15].

\section{Results and Discussions}

Plant oils have recently become one of the most important renewable feedstocks for replacement of petroleum-based sources in the chemical industry. In the synthesis of biobased polymers, plant oils are widely used due to their broad availability, 
biodegradability, low cost, non-toxicity, and ability to undergo diverse organic reactions [16-20]. Organic reactions of transformation of triglycerides into different fatty derivatives have been considered, particularly in the synthesis of renewable biobased monomers and further polymerization to develop polymers and polymeric materials [21].

Recently, we developed a one-step method of plant oil direct transesterification into vinyl monomers for free radical polymerization and copolymerization $[11-13,22]$. It was demonstrated that the rate of POBM homopolymerization, where chain propagation coexists with chain transfer reaction on monomers, is determined primarily by the amount of unsaturation in each plant oil triglycerides. In the next step, stable latexes containing up to $50 \mathrm{wt} \%$ of plant oil-based content were synthesized using miniemulsion copolymerization of POBM with their petroleum-based counterparts [13].

For this study, monomers from olive (OVM) and soybean (SBM) oils were chosen to investigate plasticization effect and the impact of monomer unsaturation on latex film properties. The choice of POBM was based on a considerable difference in unsaturation of fatty acid fragments in OVM and SBM. It was demonstrated in our previous work that $C_{M}$ (ratio of chain transfer and propagation rate constants) depends on monomer unsaturation. This value is larger for more unsaturated SBM $\left(C_{M, O V M}=0.15, C_{M, S B M}=0.26\right)$ [13]. It has also been demonstrated that monomer unsaturation amount $\left(U_{M F}\right)$ impacts resulting copolymer molecular weight and can be used as a parameter for comparing physico-chemical and thermomechanical properties of latex films. For this purpose, a series of latexes were synthesized from OVM and SBM in miniemulsion copolymerization with St and MMA.

Miniemulsion copolymerization of POBM with petroleum-based comonomers yields latexes with an average particle size of $50-100 \mathrm{~nm}$ and $7-55 \mathrm{wt} \%$ of biobased content, exhibiting stability at room temperature within several months.
Table 1. Characteristics of Latexes from POBM and MMA.

\begin{tabular}{|c|c|c|c|c|c|}
\hline $\begin{array}{c}\text { Biobased content, } \\
\% \text { wt. }\end{array}$ & \multirow{2}{*}{$\mathrm{S}^{*}, \%$} & $\begin{array}{c}\text { Latex } \\
\text { solid } \\
\text { content } \\
, \%\end{array}$ & $\begin{array}{c}\mathrm{M}_{\mathrm{n}}, \\
\mathrm{g} / \mathrm{mol} / \mathrm{PDI}\end{array}$ & $\begin{array}{c}\mathrm{T}_{\mathrm{g}} \text {, } \\
{ }^{\circ} \mathrm{C}\end{array}$ \\
\hline 10 OVM & 6.5 & 97 & 39 & $152,200 / 4.3$ & 98 \\
\hline 20 OVM & 14.3 & 94 & 29 & $82,100 / 3.1$ & 93 \\
\hline 40 OVM & 33.4 & 87 & 23 & $95,600 / 5.2$ & 63 \\
\hline 10 SBM & 6.9 & 92 & 37 & $81,230 / 6.7$ & 97 \\
\hline 20 SBM & 14.2 & 91 & 28 & $39,200 / 4.0$ & 88 \\
\hline 40 SBM & 32.2 & 81 & 22 & $34,400.3 .5$ & 57 \\
\hline
\end{tabular}

$*$ S- total monomer conversion

Table 2. Characteristics of Latexes from POBM and St.

\begin{tabular}{|c|c|c|c|c|c|}
\hline \multicolumn{2}{|c|}{$\begin{array}{c}\text { Biobased content, } \\
\% \text { wt. }\end{array}$} & \multirow{2}{*}{$\mathrm{S}^{*}, \%$} & $\begin{array}{c}\text { Latex } \\
\text { solid } \\
\text { content } \\
, \%\end{array}$ & $\mathrm{M}_{\mathrm{n}, \mathrm{g} / \mathrm{mol} / \mathrm{PDI}}$ & $\begin{array}{c}\mathrm{T}_{\mathrm{g}} \\
{ }^{\circ} \mathrm{C}\end{array}$ \\
\hline feed & polymer & & & & \\
\hline 25 OVM & 20.3 & 89 & 34 & $180,000 / 4.9$ & 84 \\
\hline 40 OVM & 30.1 & 83 & 30 & $168,000 / 3.1$ & 57 \\
\hline 60 OVM & 46.0 & 82 & 40 & $117,000 / 4.6$ & 39 \\
\hline 25 SBM & 56.5 & 80 & 34 & $108,500 / 3.2$ & 18 \\
\hline 40 SBM & 15.5 & 79 & 29 & $119,500 / 4.8$ & 75 \\
\hline 50 SBM & 28.0 & 73 & 29 & $65,100 / 3.8$ & 50 \\
\hline 60 SBM & 56.1 & 64 & 29 & $58,000 / 2.7$ & 27 \\
\hline
\end{tabular}

*S- total monomer conversion

Characteristics of resulting materials (Tables 1 and 2) show that latexes with a polymer content of 22$40 \%$ and monomer conversion of $65-95 \%$ were obtained. Conversion varies with a POBM unsaturation amount in feed (higher conversion was obtained in copolymerization of less unsaturated OVM for both St and MMA).

As Tables 1 and 2 indicate, biobased content (determined using ${ }^{1} \mathrm{H}$ NMR spectroscopy) in resulting latexes only slightly deviated from the POBM content in monomer feed, confirming that waste majority of plant oil-based ingredients is incorporated into the copolymer macromolecules during miniemulsion polymerization.

As expected, molecular weight of the resulting latex copolymers decreased with an increasing POBM concentration in monomer feed. Molecular weight follows poly(MMA-Co-OVM) > poly(MMA-Co-SBM), as well as poly(St-co-OVM) > poly(MMA-co-SBM), corresponding to increasing unsaturation amounts of POBM. A similar effect was observed by increasing the fraction of plant oil-monomer in the initial mixture in our previous study [11-13,22]. Decreasing molecular 
weight is explained by effect of degradative chain transfer on the monomer (allylic termination) provided by differing numbers of allylic hydrogen atoms in the monomer molecules. The latter effect is more pronounced for reactions of SBM compared to OVM.

Analysis on $T_{g}$ data measured by DSC (Tables 1 and 2) showed that the presence of plant oil-based fragments in latex copolymers decreases glass transition temperature, and thus, plasticizes the polymers. As a result of internal plasticizing effect (due to the presence of unsaturated POBM fragments), the synthesized latex copolymers are considerably more flexible compared to poly(methyl methacrylate) $\left(\mathrm{PMMA} ; T_{g}=105^{\circ} \mathrm{C}\right.$ ) and polystyrene (PS; $T_{g}=100^{\circ} \mathrm{C}$ ) homopolymers.

Extent of the transforming rigid PSt and PMMA into film-forming flexible polymers depends on POBM chemical structure. To this end, a more pronounced change of $T_{g}$ for more unsaturated SBM-based latexes was observed compared to OVM-based copolymers. In this regard, Tables 1 and 2 indicate that incorporation of $7-55 \mathrm{wt} \%$ of SBM/OVM fragments in copolymer decreased the $T_{g}$ of latex films at about $95^{\circ} \mathrm{C}$ for SBM and $80^{\circ} \mathrm{C}$ for OVM in copolymerization with $\mathrm{St}$, as well as at about $48^{\circ} \mathrm{C}$ for $\mathrm{SBM}$, and $43^{\circ} \mathrm{C}$ for $\mathrm{OVM}$ in copolymerization with MMA.

Overall decrease in $T_{g}$ corresponds to the biobased content in the resulting macromolecules and is more pronounced for latexes with higher plant oilbased amounts.

To explain the difference in plasticizing effect of SBM and OVM-based fragments, unsaturation amount and chemical structure of both monomers should be considered. SBM consists predominantly of more unsaturated linoleic fatty acid fragments (with two double bonds), while OVM contains mostly oleic acid fragments (with one double bond). To this end, being incorporated in the copolymers with MMA and St, more unsaturated fragments of SBM present a spatial arrangement that diminishes the packing ability of macromolecules due to the macromolecular configuration and, thus, the plasticizing effect is more expressed in SBM-based latexes.

Crosslinking is often applied to improve polymer properties and design materials for specific purposes and applications. In this regard, mechanical properties of polymeric materials, such as hardness, elongation at break $\left(\varepsilon_{\mathrm{b}}\right)$, and Young's modulus $(E)$, essentially depend on crosslink density $(v)$, which particularly depends on the structure of a polymer network [23]. In fact, the mobility of polymer chains in a crosslinked network is a function of $v$ and determines the mechanical and thermal properties of polymeric materials. To characterize homogeneous polymer networks, linear viscoelastic behavior (polymer response to a periodic force and polymer deformation at this force) can be determined using DMA to calculate crosslink density. To provide further insights into the plasticizing effect of oil-based fragments, the tensile properties of films from the latexes synthesized in this study were evaluated at room temperature.

As an additional parameter, effective molecular weight between crosslinking nodes $\left(M_{c}\right)$ in polymer network was calculated using density of latex copolymers from POBM and St: $\rho$ (poly[OVM-St]) = $0.955 \mathrm{~g} / \mathrm{mol}, \rho$ (poly $[\mathrm{SBM}-\mathrm{St}])=0.970 \mathrm{~g} / \mathrm{mol}$ (Table 3$)$.

Table 3. Molecular weight between crosslinks $\left(M_{c}\right)$ in polymer networks from POBM and St.

\begin{tabular}{|c|c|c|c|c|}
\hline $\begin{array}{c}\text { Biobased } \\
\text { latex }\end{array}$ & 50 OVM & 60 OVM & 50 SBM & 60 SBM \\
\hline$M_{c}, \mathrm{~g} / \mathrm{mol}$ & 8,300 & 5,600 & 4,800 & 3,700 \\
\hline
\end{tabular}

From the DMA data, the value of storage modulus $G^{\prime}$ in rubber elasticity region (at $T>\left[T_{g}+50^{\circ} \mathrm{C}\right]$ ) was determined from a $\tan \delta$ plot to calculate crosslink density $(v)$. In addition, Young's modulus $(E)$, tensile strength $(\sigma)$ and elongation at break $\left(\varepsilon_{b r}\right)$ were measured to characterize mechanical properties of the crosslinked latex films and demonstrate plasticizing effect of POBM fragments. The obtained results showed that crosslink density of latex polymer network noticeably depends on POBM content in monomer feed and latex copolymers. Increasing the unsaturation amount in monomer feed led to increasing $v$ (Figure 1) and, respectively, decreasing $M_{c}$ (Table 3 ). The obtained data indicated that crosslink density of POBM-based latex films can be controlled by monomer feed unsaturation amount, as well as by nature (chemical structure) of POBM. 


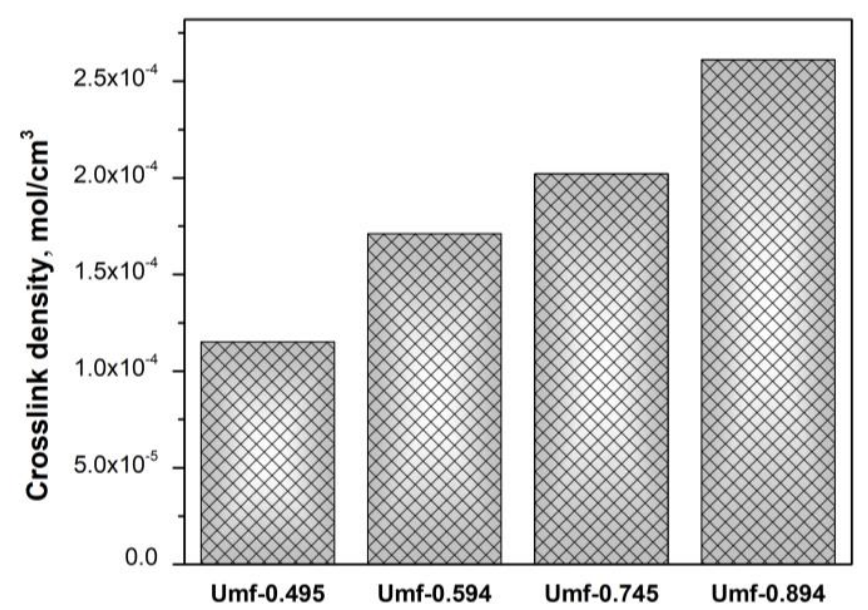

Figure 1. Crosslink density vs. unsaturation amount $\left(U_{M F}\right)$ and vs. plant oil-based content in monomer feed.

Table 4. Tensile Properties of Latex Films from OVM and SBM Copolymerized with MMA.

\begin{tabular}{|c|c|c|c|c|}
\hline $\begin{array}{c}\text { Biobased } \\
\text { latex }\end{array}$ & $E, \mathrm{MPa}$ & $\sigma, \mathrm{MPa}$ & $\varepsilon_{b r}, \%$ & $\begin{array}{c}U_{T}, \times 10^{-4} \\
\mathrm{~J} / \mathrm{m}^{3}\end{array}$ \\
\hline 20 OVM & $420 \pm 45$ & 1.4 & 0.7 & 1.8 \\
\hline 40 OVM & $131 \pm 30$ & 3.3 & 243 & 180 \\
\hline $20 \mathrm{SBM}$ & $1159 \pm 6$ & 11.3 & 1.3 & 5.2 \\
\hline $40 \mathrm{SBM}$ & $171 \pm 38$ & 3.1 & 68.1 & 6.7 \\
\hline
\end{tabular}

Table 5. Tensile Properties of Latex Films from OVM and SBM Copolymerized with St.

\begin{tabular}{|c|c|c|c|c|}
\hline $\begin{array}{c}\text { Biobased } \\
\text { latex }\end{array}$ & $E, \mathrm{MPa}$ & $\sigma, \mathrm{MPa}$ & $\varepsilon_{b r}, \%$ & $\begin{array}{c}U_{T,} \times 10^{-4}, \\
\mathrm{~J} / \mathrm{m}^{3}\end{array}$ \\
\hline 25 OVM & 710 & 8.8 & 4 & 15 \\
\hline 40 OVM & 290 & 4.4 & 24 & 25 \\
\hline 50 OVM & 92 & 3.3 & 245 & 130 \\
\hline 60 OVM & 2.1 & 2.3 & 275 & 170 \\
\hline 25 SBM & 890 & 6.9 & 1 & 2 \\
\hline 40 SBM & 550 & 5.9 & 9 & 28 \\
\hline 50 SBM & 220 & 5.7 & 130 & 31 \\
\hline 60 SBM & 6.3 & 3.5 & 128 & 105 \\
\hline
\end{tabular}

Tables 4 and 5 show that although Young's modulus and tensile strength both decrease by increasing the biobased content, elongation at break increases significantly for all co-monomer pairs. The obtained data indicated that presence of plant oil-based fragments makes latex films much softer and increases toughness $\left(U_{T}\right)$ of the material. The latter is much more pronounced when petroleum-based monomers are copolymerized with less unsaturated OVM compared to MMA and St reacted with SBM. The data confirmed that being incorporated into the copolymer, acrylic monomers from plant oils perform as internal plasticizers of crosslinked latex films and reduce intermolecular interactions between macromolecules.

As a result, $\varepsilon_{b r}$ of latex films increases from a few $\%$ (for PS and PMMA) up to 275\% (for films from St and $60 \mathrm{wt} \%$ OVM). Overall, higher $\varepsilon_{b r}$ was recorded for OVMbased latexes compared to SBM-containing polymer films due to the formation of shorter crosslinks between nodes in the polymer network that correlate with higher crosslink degree (Table 3).

At the same biobased content in copolymers, higher Young's modulus and tensile strength were observed for latex films from both PS and PMMA and more unsaturated SBM compared to films from OVMcontaining latexes. This can be explained by higher crosslink density (due to higher amount of unsaturation) of SBM-based latex films and corresponding higher elastic deformation.

For a more comprehensive understanding of the effect of POBM structure on material performance, model coatings were prepared from latexes synthesized in copolymerization of MMA and 50 wt. \% each of OVM and SBM. Resulting coatings were characterized in terms of flexibility, hardness, and adhesion to the metal surface, according to ASTM methods.

In the crosshatch adhesion test (ASTM 3359), coating adhesion to the substrate was identified on a scale of 0 to 5 , where 0 indicates no adhesion and 5 indicates high adhesion.

Figure 2 shows that POBM structure (monomer unsaturation amount) impacts adhesion of the latex coating to the metal. Better adhesion was observed for coatings made from more unsaturated SBM-containing latexes.

As can also be seen from Figure 2, the pendulum hardness of the crosslinked latex films changes with the POBM's unsaturation amount and crosslink density. Resulting hardness was higher for the polymer network formed from more unsaturated POBM SBM copolymerized with MMA.

In addition to improving mechanical properties of latex films, plant oil-based fragments can enhance water resistance by increasing hydrophobicity of the film (coatings) made from latex. In fact, aqueous emulsions often need to be modified because of inherently poor properties with respect to water resistance. Water molecules act as plasticizers in such latex films and worsen their mechanical properties; thus, hydrophobic 
additives are often needed to reduce water sensitivity of the polymer.
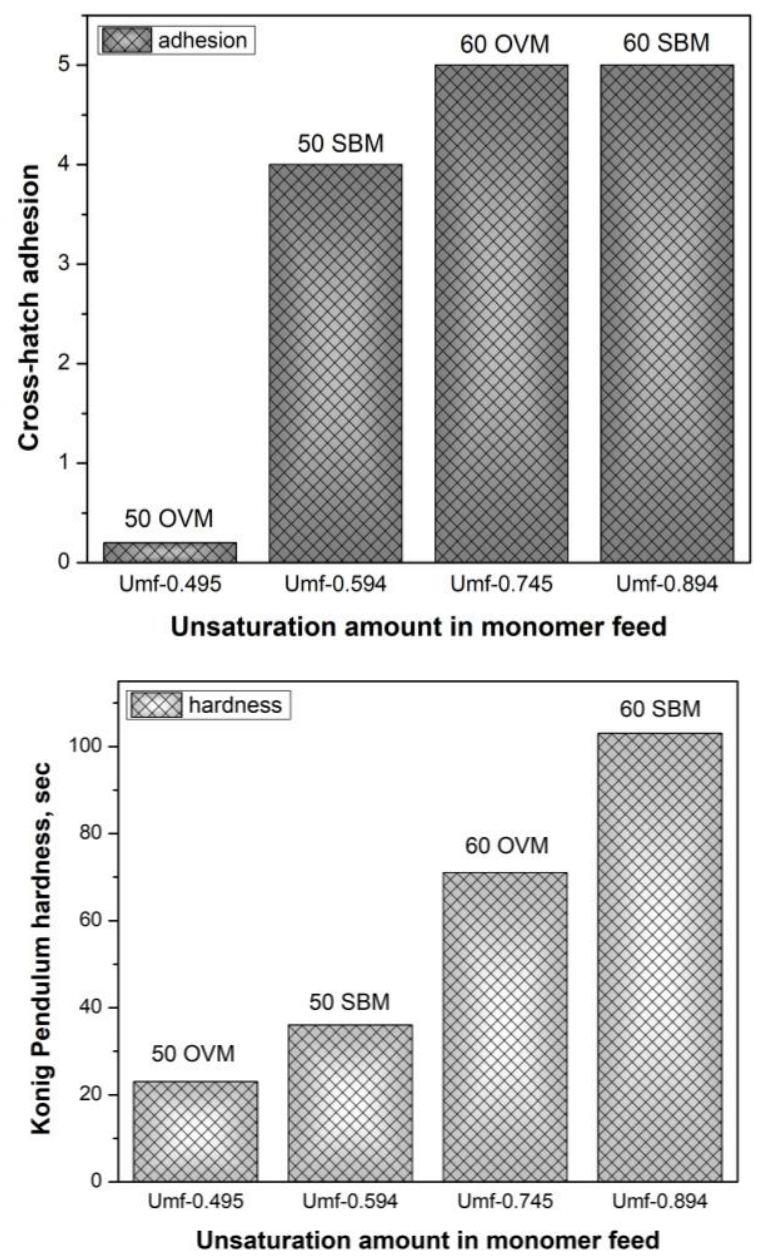

Figure 2. The effect of monomer structure on properties of latex coatings.

To determine the extent of hydrophobicity provided by the presence of POBM fragments to latex films, water and diiodomethane contact angles (CA; Table 6) were measured and surface energy was calculated for coatings formulated from latexes synthesized in copolymerization of MMA with 40wt\% each of OVM and SBM.

Coatings made from plant oil-based latexes are indeed more hydrophobic compared to PMMA homopolymer (Table 6). Water contact angle raised from $68^{\circ}$ for PMMA up to $95^{\circ}$ for $40 \mathrm{wt} \%$ SBM copolymer. Differences in water contact angle and surface energy were observed for coatings made from latexes based on SBM in comparison to OVM. SBMcontaining coatings (biobased fragments with higher unsaturation amounts) were more hydrophobic compared to material with same weight fraction of less unsaturated OVM.

Table 6. Surface energy of latex films from copolymers of MMA and OVM or SBM.

\begin{tabular}{|c|c|c|c|c|c|c|}
\hline Bio- & Film & \multirow{2}{*}{$\begin{array}{c}\text { based } \\
\text { coating }\end{array}$} & $\begin{array}{c}\text { thickness, } \\
\mu \mathrm{m}\end{array}$ & $\begin{array}{c}\text { Water } \\
\mathrm{CA}, \theta,{ }^{\circ}\end{array}$ & \multirow{2}{*}{$\begin{array}{c}\mathrm{CH}_{2} \mathrm{I}_{2} \\
\mathrm{CA}, \theta,\end{array}$} & \multicolumn{3}{|c|}{$\begin{array}{c}\text { Surface } \\
\text { energy, } \mathrm{N} / \mathrm{m}\end{array}$} \\
\cline { 5 - 8 } & $\lambda_{S^{\mathrm{d}}}$ & $\lambda_{S^{\mathrm{h}}}$ & $\lambda_{\mathrm{S}}$ \\
\hline 40 OVM & $35 \pm 7$ & 80 & 46 & 32 & 5 & 37 \\
\hline 40 SBM & $31 \pm 5$ & 95 & 55 & 30 & 1 & 31 \\
\hline
\end{tabular}

* Surface energy of PMMA- 41,0 N/m

This finding can be explained by formation of a polymer network with higher density, which enhances the effect of incorporated hydrophobic fatty acid fragments into the latex coatings. The calculated surface energy for POBM-based copolymers decreases in comparison to PMMA homopolymer (Table 6), indicating that presence of POBM fragments can be beneficial for formation of low surface energy latex materials when water repellent properties are needed.

\section{Conclusion}

Latex nanoparticles from acrylic monomers (synthesized from olive and soybean oil and different in terms of triglyceride fatty acids unsaturation) were prepared by miniemulsion copolymerization with St and MMA. Decreasing glass transition temperature of latex copolymers indicated that the presence of plant oil-based fragments impacts the thermomechanical properties of resulting copolymers by providing strong plasticizing effects. Plant oil-based ingredients make the copolymers more flexible, improve film-forming properties, and provide toughness compared to the normally rigid PS and PMMA.

It has been demonstrated that the unsaturation amount of the POBM (corresponding to the chemical structure of the oil) can be utilized as a reliable experimental parameter in controlling resulting latex properties, including the influence of variation in monomer feed unsaturation on the crosslink density of latex films and, consequently, polymer thermal and mechanical properties.

In addition, it has been shown that plant oil-based fragments enhance hydrophobicity of the latex film coatings; thus, these can be considered as additives to reduce water sensitivity of the polymer materials (coatings). 
Assuming ability of POBMs to act as internal plasticizers by making the polymer material more flexible and to enhance hydrophobicity of the polymer films, as well as the broad availability of plant/vegetable oils for synthesis of new monomers, this study can be considered a promising platform for improving properties of latex polymers and latex polymer networks in various applications, including coatings and paints.

\section{References}

[1] F. T. Sejidov, Y. Mansoori, N. Goodarzi, "Esterification reaction using solid heterogeneous acid catalysts under solvent-less condition" Journal of Molecular Catalysis A: Chemical, vol. 240, no. 12, pp. 186-190, 2005.

[2] E. Białecka-Florjanczyk, Z. Florjanczyk, "Solubility of plasticizers, polymers and environmental pollution" in Thermodynamics, Solubility and Environmental Issues, Letcher T, Eds. New York: Elsevier; 2007, pp. 397-408.

[3] S. L. Rosen, Fundamental principles of polymeric materials. New York: John Wiley \& Sons, Inc., 1993 pp. 82-101.

[4] L. Savenkova, Z. Gercberga, V. Nikolaeva, A. Dzene, I. Bibers, M. Kalnin, "Mechanical properties and biodegradation characteristics of PHB-based films," Process Biochemistry, vol. 35, no. 6, pp. 573579, 2000.

[5] K. Pielichowski, B. Swierz-Motysia, "Influence of polyesterurethane plasticizer on the kinetics of poly(vinyl chloride) decomposition process," Journal of Thermal Analysis and Calorimetry, vol. 83, no. 1, pp. 207-212, 2006.

[6] O. Fenollar, L. Sánchez-Nacher, D. GarcíaSanoguera, J. López, R. Balart, "The effect of the curing time and temperature on final properties of flexible PVC with an epoxidized fatty acid ester as natural-based plasticizer," Journal of Materials Science, vol. 44, no. 14, pp. 3702-3711, 2009.

[7] M. Vieira, M. Silva, L. Santos, M. Beppu "Naturalbased plasticizers and biopolymer films: A review" European Polymer Journal, vol. 47, no. 3, pp. 254263, 2011.

[8] H. Baltacioglu, D. Balköse, "Effect of zinc stearate and/or epoxidized soybean oil on gelation and thermal stability of PVC-DOP plastigels" Journal of Applied Polymer Science, vol. 74, no. 10, pp. 248898, 1999.

[9] J. S. Choi, W. H. Park, "Effect of biodegradable plasticizers on thermal and mechanical properties of poly(3-hydroxybutyrate)," Polymer Testing, vol. 23, no. 4, pp. 455-460, 2004.

[10] M. José Fabra, P. Talens, A. Chiralt, "Tensile properties and water vapor permeability of sodium caseinate films containing oleic acid-bees wax mixtures," Journal of Food Engineering, vol. 85, no. 3, pp. 393-400, 2008.

[11] Z. Demchuk, O. Shevchuk, I. Tarnavchyk, V. Kirianchuk, M. Lorenson, A. Kohut, S. Voronov, A. Voronov, "Free Radical Copolymerization Behavior of Plant Oil-Based Vinyl Monomers and Their Feasibility in Latex Synthesis," ACS Omega, no. 1. pp. 1374-1382, 2016.

[12] Z. Demchuk, A. Kohut, S. Voronov, A. Voronov, "Versatile platform for controlling properties of plant oil- based polymer networks," ACS Sustainable Chemistry \& Engineering, vol. 6, no. 2, pp. 27802786, 2018.

[13] Z. Demchuk, O. Shevchuk, I. Tarnavchyk, V. Kirianchuk, A. Kohut, S. Voronov, A. Voronov, "Free radical polymerization behavior of the vinyl monomers from plant oil triglycerides," ACS Sustainable Chemistry \& Engineering, vol. 4, no. 12, pp. 6974-6980, 2016.

[14] H. Ishida, D. J. Allen, "Mechanical characterization of copolymers based on benzoxazine and epoxy," Polymer, vol. 37, no. 20, pp. 4487-4495, 1996.

[15] M. Żenkiewicz "Methods for the calculation of surface free energy of solids," Journal of Achievements in Materials and Manufacturing Engineering vol. 24, no. 1, pp. 137-145, 2007.

[16] R. G. Verhe, "Industrial products from lipids and proteins," in Renewable Bioresources: Scope and Modification for Non-Food Applications, C. V. Stevens, R. G. Verhe, Eds. John Wiley \& Sons, Ltd., Chichester, 2004, p. 328.

[17] F. S. Guner, Y. Yagci, A. T. Erciyes, "Polymers from triglyceride oils," Progress in Polymer Science, vol. 31, no. 7, pp. 633-670, 2006.

[18] V. Sharma, P. P. Kundu, "Addition Polymers from Natural Oils-A Review," Progress in Polymer Science, vol. 31, no. 11, pp. 983-1008, 2006.

[19] R. P. Wool, X. S. Sun, Bio-Based Polymers and Composites. Elsevier, Amsterdam, 2005, p. 620.

[20] F. Gunstone, Fatty acid and lipid chemistry. Blackie Academic \& Professional, New York, 1996, p. 252.

[21] M. E. Borges, I. Diaz, "Recent Developments of Heterogeneous Catalysts for Biodiesel Production by Oil Esterification and Transesterification Reactions: A Review," Renewable and Sustainable Energy Reviews, vol. 16, no. 5, pp. 2839-2849, 2012. 
[22] K. Kingsley, O. Shevchuk, S. Voronov, A. Voronov, "Features of Emulsion Copolymerization for Plant Oil-Based Vinyl Monomers and Styrene," Industrial Crops and Products, vol. 109, pp. 274-280, 2017.

[23] A. Zosel, G. Ley, "Influence of Cross-Linking on Structure, Mechanical Properties, and Strength of Latex Films," Macromolecules, vol. 26, no. 9, pp. 2222-2227, 1993. 